\title{
Correction to: Ultrasensitive Nanosensor for Detection of Malic Acid in Tomato as Fruit Ripening Indicator
}

\author{
Anita Dalal ${ }^{1,2} \cdot$ J. S. Rana ${ }^{2} \cdot$ Ashok Kumar $^{1}$ \\ Published online: 3 January 2018 \\ (C) Springer Science+Business Media, LLC, part of Springer Nature 2017
}

Correction to: Food Anal. Methods (2017) 10(11):3680-3686
https://doi.org/10.1007/s12161-017-0919-x

The original version of this article unfortunately contained mistakes. In Figs. 2a, c and 5a in which Y-axis (Current X10 ${ }^{3}$ ) should not be written. It should only be "Current". The correct version of Figs. 2a, c and 5a are given below.

The online version of the original article can be found at https://oi.org/ 10.1007/s12161-017-0919-x.

\footnotetext{
Ashok Kumar

ashokigib@rediffmail.com

1 CSIR-Institute of Genomics and Integrative Biology, Mall Road, Delhi 110007, India

2 Deenbandhu Chhotu Ram University of Science and Technology, Murthal, Sonepat, Haryana 131039, India
} 


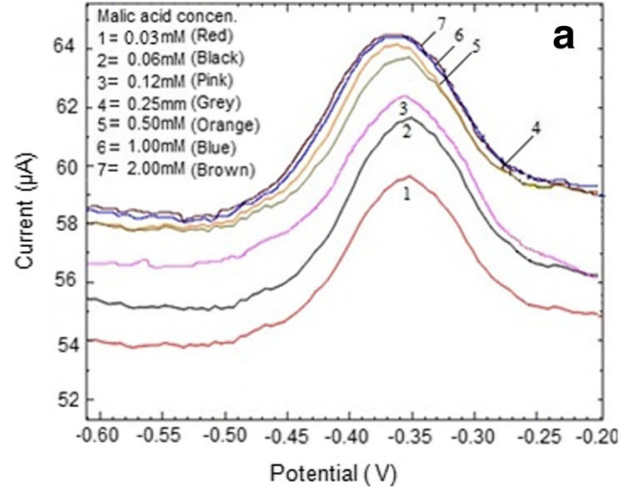

Fig. 2 a DPV response of enzyme/c-MWCNT electrode at different concentrations of malic acid in PBS, pH 7.4. b Measurement of DPV at variable malic acid concentrations on immobilized malic enzyme/c-

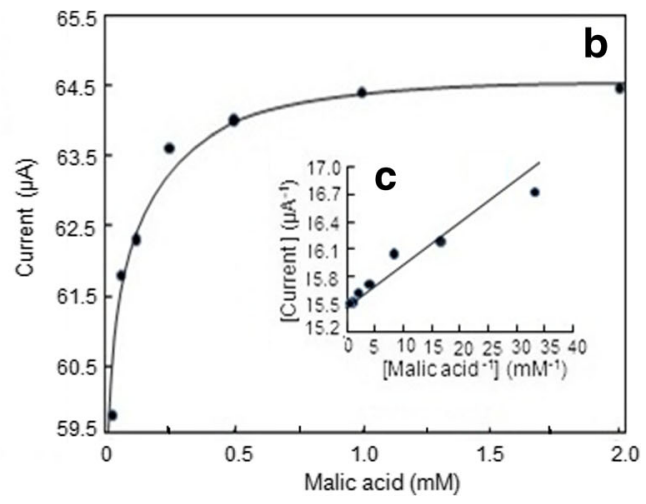

MWCNT electrode. Inset $\mathbf{c}$ Lineweaver-Burk plot for determination of $\mathrm{K}_{\mathrm{m}}$ of nanosensor based on NADP-malate dehydrogenase immobilized on c-MWCNT electrode
Fig. 5 a $\mathrm{CV}$ of malic acid at different stages of ripening of tomato. b DPV of malic acid at different stages of ripening of tomato
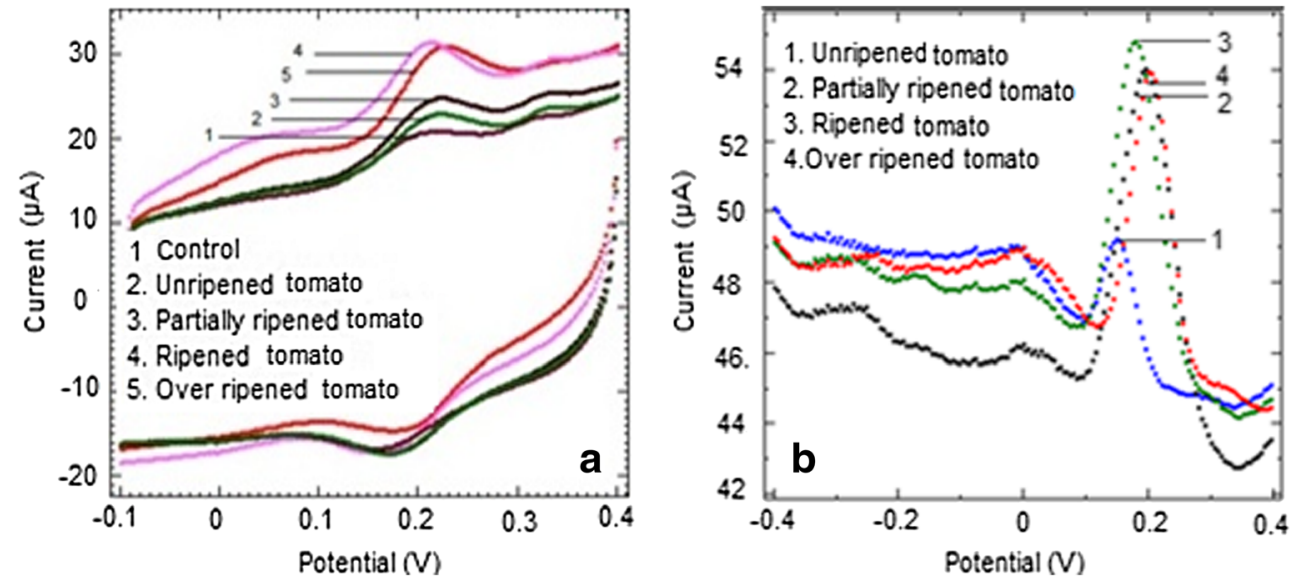